\title{
Feasibility Study on Facile and One-step Colorimetric Determination of Glutathione by Exploiting Oxidase-like Activity of $\mathrm{Fe}_{3} \mathrm{O}_{4}-\mathrm{MnO}_{2}$ Nanocomposites
}

\author{
Huiwen Zhang, ${ }^{*}$ Shuo Yao, ${ }^{*}$ Chao Zhao, ${ }^{*}$ Wei Zhao, ${ }^{* *}$ Juan Li, ${ }^{* \dagger}$ and Juan WAng** \\ *School of Public Health, Jilin University, Changchun 130021, China \\ **Jilin Provincial Center for Disease Control and Prevention, Changchun 130062, China
}

\begin{abstract}
A facile and one-step colorimetric assay is described for the determination of glutathione (GSH). It is based on the use of manganese dioxide-decorated magnetic $\left(\mathrm{Fe}_{3} \mathrm{O}_{4} @ \mathrm{MnO}_{2}\right)$ nanocomposite that was prepared by an in-situ redox reaction. It exhibits oxidase-mimicking activity and can catalyze the oxidation of $3,3^{\prime}, 5,5^{\prime}$-tetramethylbenzidine (TMB) without $\mathrm{H}_{2} \mathrm{O}_{2}$ to form a blue colored product (oxTMB) with an absorption maximum at $651 \mathrm{~nm}$. Once GSH is introduced, the component of $\mathrm{MnO}_{2}$ can be rapidly reduced to $\mathrm{Mn}^{2+}$ ions, which leads to inhibit the formation of oxTMB. Based on these findings, a one-step colorimetric assay was developed for the detection GSH in the range of 0.2 to $25 \mu \mathrm{M}$ with a low detection limit of $0.2 \mu \mathrm{M}$ without using any procedures of separation and washing. Importantly, the proposed approach is also used to accurately evaluate the intracellular GSH levels. In our perception, the assay is rapid, sensitive and specific.
\end{abstract}

Keywords $\mathrm{Fe}_{3} \mathrm{O}_{4}-\mathrm{MnO}_{2}$ nanocomposite, oxidase-like, glutathione, cell lines, visual detection

(Received September 23, 2020; Accepted February 18, 2021; Advance Publication Released Online by J-STAGE March 5, 2021)

\section{Introduction}

Glutathione (GSH) is the most abundant intracellular biothiol, which consists of a tripeptide of glutamic acid, cysteine, and glycine. ${ }^{1}$ It plays a crucial role in the defense of cells against free radicals and other electrophiles, and is involved in intracellular signal transduction, gene regulation and xenobiotic metabolism. ${ }^{2,3}$ An abnormal level of GSH is considered to be a reliable sign of some diseases, such as cancer, AIDS, liver damage, diabetes, and aging. ${ }^{4,5}$ Therefore, based on its biological and clinical importance, the rapid and sensitive detection of GSH in cells for early diagnosis has attracted continuing great interest.

Umezara et al. developed FRET-based ratiometric probes to quantify the GSH concentration in various cell types while enabling real-time live cell imaging of GSH dynamics in seconds, which pioneered the rapid detection of GSH. ${ }^{6}$ In addition, a variety of analytical methods, including highperformance liquid chromatography (HPLC), liquid chromatography coupled with tandem mass-spectrometry (LCMS/MS), and spectrofluorimetry, ${ }^{7-9}$ have been established for the determination of GSH. However, these methods are timeconsuming and require tedious sample pre-treatments, highly qualified professional technicians and sophisticated instruments, ${ }^{10}$ making them inconvenient for practical use in certain circumstances. Thus, colorimetric analytical strategies have aroused special attention due to their simple, rapid, cost-

† To whom correspondence should be addressed.

E-mail: jwang0723@jlu.edu.cn (J. W.); li_juan@jlu.edu.cn (J. L.) effective detection without any advanced apparatus. ${ }^{11-13}$ One of the most common types of colorimetric methods focuses on enzyme-chromogenic substrates. The limitation of the high-cost and low stability under harsh environmental conditions makes natural enzymes to be restricted to analytical applications. As alternatives, nanozymes are a class of synthetic nanomaterials based on carbon, ${ }^{14}$ metal oxides, ${ }^{15}$ or noble metals ${ }^{16}$ with enzyme-like characteristics, which have become increasingly important research tools in recent years.

Compared to noble metal oxides, ferroferric oxide nanoparticles $\left(\mathrm{Fe}_{3} \mathrm{O}_{4} \mathrm{NPs}\right)$ as a typical kind of transition-metal oxides have received tremendous attention due to an outstanding peroxidase-like activity, low-cost, and non-toxicity. ${ }^{17,18}$ However, the $\mathrm{Fe}_{3} \mathrm{O}_{4}$ nanozyme-based catalytic Fenton reaction typically requires a high dose of $\mathrm{H}_{2} \mathrm{O}_{2}$ (approximately $10^{-3}$ to $\left.10^{-4} \mathrm{M}\right),{ }^{19,20}$ due to its low affinity to the substrate $\mathrm{H}_{2} \mathrm{O}_{2}$. Because $\mathrm{H}_{2} \mathrm{O}_{2}$ as an oxidant is unstable to the surrounding environment and may damage target analytes, ${ }^{21}$ which makes a peroxidase-like activity of the $\mathrm{Fe}_{3} \mathrm{O}_{4}$ NPs-based nanozyme unviable for practical use. Fortunately, manganese dioxide $\left(\mathrm{MnO}_{2}\right)$ NPs with high intrinsic oxidase-like activity have been developed to address this problem, ${ }^{22}$ which can catalytically oxidize the substrate $3,3^{\prime}, 5,5^{\prime}$-tetramethylbenzidine (TMB) without $\mathrm{H}_{2} \mathrm{O}_{2}$ to produce a blue color with a maximum absorption peak at $651 \mathrm{~nm} \cdot{ }^{23,24}$ However, when detecting GSH by $\mathrm{MnO}_{2} \mathrm{NPs}$, there were still some drawbacks, such as the containing noble metal nanoparticles in the sensing system, ${ }^{25}$ or requiring extremely acidic reaction conditions, ${ }^{26}$ which is not conducive to its promotion and application in practical projects. To overcome these drawbacks, we combined the advantages of the $\mathrm{Fe}_{3} \mathrm{O}_{4}$ NPs and $\mathrm{MnO}_{2}$ NPs, and designed a new class of 


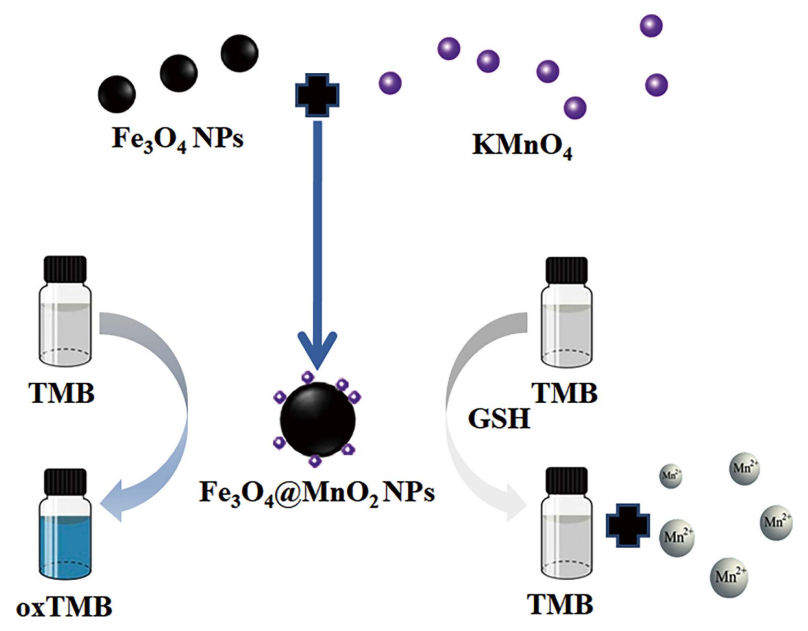

Scheme 1 Schematic diagram of the proposed colorimetric assay for GSH detection in cell lines based on the inhibition effect of GSH on the oxidase-like activity of $\mathrm{Fe}_{3} \mathrm{O}_{4} @ \mathrm{MnO}_{2}$ nanocomposite.

hybrid nanomaterials based on them. This has been extensively developed, owing to its easy magnetic separation capability and high catalytic activity. ${ }^{27} \quad \mathrm{Fe}_{3} \mathrm{O}_{4} @ \mathrm{MnO}_{2} \mathrm{NPs}$ synthesized by this method are easy to prepare and have high stability. Therefore, the previous findings showed that $\mathrm{Fe}_{3} \mathrm{O}_{4} @ \mathrm{MnO}_{2} \mathrm{NPs}$ are highly recommended as a novel and facile tool for colorimetric detection.

With these insights, to develop a novel approach for GSH detection and identifying cancer cells in a simple mode for relevant biomedical diagnosis, we proposed a method for the rapid and accurate detection of GSH to overcome the shortcomings of the existing methods. Scheme 1 illustrates the mechanism of the proposed method for GSH detection. $\mathrm{Fe}_{3} \mathrm{O}_{4} @$ $\mathrm{MnO}_{2}$ NPs possess strong oxidase-like activity, which can catalyze the oxidation of TMB to form a blue-colored product (oxTMB) that depends on dissolved molecular oxygen in the solution. ${ }^{28}$ Upon the addition of GSH, the component of $\mathrm{MnO}_{2}$ can be rapidly reduced to $\mathrm{Mn}^{2+}$ ions, which leads to a concentration-dependent inhibition of the formation of oxTMB. 29,30 Based on these results, the intensity of the absorption maximum at $651 \mathrm{~nm}$ was proportionally decreased. ${ }^{23,29}$ Based on the colorimetric method, it has been proven to be sensitive and selective to GSH in aqueous solution and living cells. Importantly, our one-step approaches mean there is no need for any procedures of separation and washing, no needs for $\mathrm{H}_{2} \mathrm{O}_{2}$, and has no special requirement for the $\mathrm{pH}$ and temperature. Taking advantage of the easy preparation and high stability of $\mathrm{Fe}_{3} \mathrm{O}_{4} @ \mathrm{MnO}_{2} \mathrm{NPs}$, the detection limit of this assay was as low as $0.2 \mu \mathrm{M}$ and the total detection time was $25 \mathrm{~min}$.

\section{Experimental}

The details of the materials, the protocol for synthesizing the $\mathrm{Fe}_{3} \mathrm{O}_{4} @ \mathrm{MnO}_{2}$ magnetic nanocomposites and the detection of GSH in living cells were described in Supporting Information.

\section{Determination of GSH}

A typical colorimetric procedure by using $\mathrm{Fe}_{3} \mathrm{O}_{4} @ \mathrm{MnO}_{2} \mathrm{NPs}$ for GSH determination was conducted as follows: $100 \mu \mathrm{L}$ of $\mathrm{Fe}_{3} \mathrm{O}_{4} @ \mathrm{MnO}_{2}$ NPs $(100 \mu \mathrm{g} / \mathrm{mL})$ and $100 \mu \mathrm{L}$ of different GSH concentrations (from 0.2 to $25 \mu \mathrm{M}$ ) were added into $300 \mu \mathrm{L}$ of a PBS solution ( $\mathrm{pH} 7.2)$. The mixture was gently vortexed and incubated at room temperature for $20 \mathrm{~min}$. Next, 7.5 $\mu \mathrm{L}$ of TMB $(10 \mathrm{mg} / \mathrm{mL})$ was added to the above mixture. DDW was used as a negative control. After coloration for $5 \mathrm{~min}$, the absorbance of the supernatant was recorded from 420 to $800 \mathrm{~nm}$ by using a UV-Vis spectrophotometer. The total detection time of our assay was only $25 \mathrm{~min}$.

For a selectivity study, $100 \mu \mathrm{L}$ of other amino acid samples (Gly, Arg, Trp, Cys, Hcy) $(25 \mu \mathrm{M})$ was used as interfering species. The test protocol was performed as described above, except that GSH was replaced by other amino acid samples.

\section{Statistical analysis}

All of the data, except for a special label, are expressed as the means \pm standard deviations $(x \pm \mathrm{SD})$ of three parallel samples. Paired t-tests were conducted for a statistical analysis using SPSS Statistics software (Ver. 22.0, IBM, USA). The statistical significance was set at 0.05 .

\section{Results and Discussion}

\section{Characterization of $\mathrm{Fe}_{3} \mathrm{O}_{4} @ \mathrm{MnO}_{2} \mathrm{NPs}$}

$\mathrm{Fe}_{3} \mathrm{O}_{4} @ \mathrm{MnO}_{2}$ NPs were characterized by TEM, EDS, SEAD, FT-IR, XRD and VSM. TEM images (Figs. 1a and 1b) show that both $\mathrm{Fe}_{3} \mathrm{O}_{4}$ NPs and $\mathrm{Fe}_{3} \mathrm{O}_{4} @ \mathrm{MnO}_{2}$ NPs were roughly spherical in shape and well dispersed. After being decorated with $\mathrm{MnO}_{2} \mathrm{NPs}$, the average size of the NPs slightly increased from $112.0 \pm 1.4$ to $125.6 \pm 1.8 \mathrm{~nm}$. A particle composition

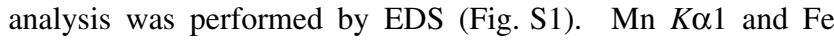
$K \alpha 1$ were observed at $\sim 6.490$ and $\sim 7.058 \mathrm{keV}$, respectively. Elemental mapping (Figs. S1c and S1d) results showed that the nanocomposites contain $\mathrm{Fe}$ and Mn elements, which is consistent with the EDS analysis. The SAED pattern (Fig. 1c) exhibits two bright concentric rings, which correspond to the (110) and (111) planes, reveal that the $\mathrm{Fe}_{3} \mathrm{O}_{4} @ \mathrm{MnO}_{2}$ NPs have a composite structure containing iron and manganese. The FT-IR spectra of $\mathrm{Fe}_{3} \mathrm{O}_{4} @ \mathrm{MnO}_{2}$ NPs is shown in Fig. 1d.

The absorption peak appearing at $3407 \mathrm{~cm}^{-1}$ is associated with the vibrations of $\mathrm{OH}$ of the absorbed water molecules. The observed bands at 1627 and $1387 \mathrm{~cm}^{-1}$ correspond to the symmetric $\mathrm{C}-\mathrm{O}$ stretching and the asymmetric stretching of $\mathrm{COO}^{-}$, respectively. The peak at $575 \mathrm{~cm}^{-1}$ corresponds to the $\mathrm{Fe}-\mathrm{O}$ stretching vibrations in iron oxide. In addition, the peaks at about 505 and $533 \mathrm{~cm}^{-1}$ are related to $\mathrm{Mn}-\mathrm{O}$ from the structure of $\mathrm{MnO}_{2} \cdot{ }^{27,31-33}$ The crystal structure of $\mathrm{Fe}_{3} \mathrm{O}_{4} @ \mathrm{MnO}_{2} \mathrm{NPs}$ was further characterized by XRD. As depicted in Fig. 1e, the position and relative intensities of peaks observed at $2 \theta$ of $18.45,30.36,35.76,43.47,63.17^{\circ}$ match perfectly to $\mathrm{Fe}_{3} \mathrm{O}_{4}$ with an inverse spinel structure, according to JCPDS data (card no. 75-0449). Diffraction peaks at $2 \theta$ of $12.74,28.74,37.6$, $42.03,46.09$ and $60.24^{\circ}$ correspond well to pure tetragonal phases of $\alpha-\mathrm{MnO}_{2}$ (JCPDS card no. 72-1982). Furthermore, concerning inheritance of the magnetic property of $\mathrm{Fe}_{3} \mathrm{O}_{4} \mathrm{NPs}$, the saturation magnetization value of $\mathrm{Fe}_{3} \mathrm{O}_{4} @ \mathrm{MnO}_{2} \mathrm{NPs}$ was $20.70 \mathrm{emu} / \mathrm{g}$ with nearly zero coercivity at room temperature (Fig. 1f). This was sufficient to accomplish a fast and efficient separation with an external magnetic field. All of these results implied that $\mathrm{Fe}_{3} \mathrm{O}_{4} @ \mathrm{MnO}_{2} \mathrm{NPs}$ were expectedly synthesized with excellent super magnetic properties.

\section{The mechanism of the sensing system}

To investigate the mimetic enzyme activity of $\mathrm{Fe}_{3} \mathrm{O}_{4} @ \mathrm{MnO}_{2}$ NPs, TMB was chosen as the chromogenic substrate in the oxidation reaction. Before verifying the mechanism of the 

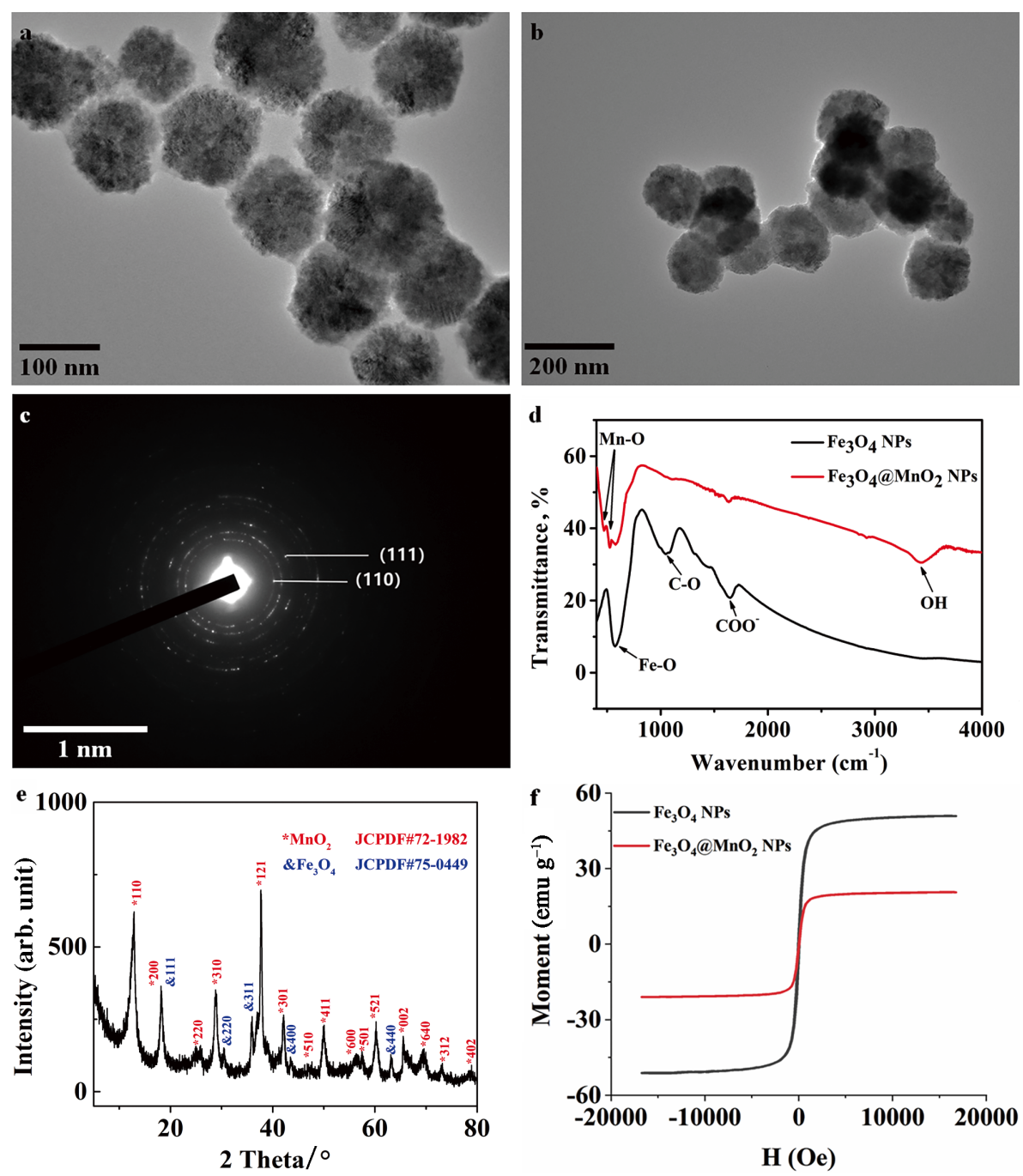

Fig. 1 Characterization of $\mathrm{Fe}_{3} \mathrm{O}_{4} @ \mathrm{MnO}_{2}$ nanocomposite. TEM images of (a) $\mathrm{Fe}_{3} \mathrm{O}_{4}$ nanoparticles and (b) $\mathrm{Fe}_{3} \mathrm{O}_{4} @ \mathrm{MnO}_{2}$ nanocomposite, (c) SAED pattern of $\mathrm{Fe}_{3} \mathrm{O}_{4} @ \mathrm{MnO}_{2}$ nanocomposite, (d) FT-IR spectra, (e) X-ray diffraction pattern, (f) magnetic hysteresis loop.

sensing system, we explored the catalytic activity of $\mathrm{Fe}_{3} \mathrm{O}_{4}$ without $\mathrm{MnO}_{2}$. According to Fig. $\mathrm{S} 2, \mathrm{Fe}_{3} \mathrm{O}_{4}$ cannot catalyze the TMB color development to form a blue final product with the absence of $\mathrm{H}_{2} \mathrm{O}_{2}$. This proved that $\mathrm{Fe}_{3} \mathrm{O}_{4}$ has no oxidase activity. As shown in Fig. 2, TMB incubated without any oxidizing agent is colorless, with no clear absorption peaks from 420 to $800 \mathrm{~nm}$ (curve I). In contrast, $\mathrm{Fe}_{3} \mathrm{O}_{4} @ \mathrm{MnO}_{2} \mathrm{NPs}$ can catalyze the oxidation of TMB in the presence of dissolved oxygen and produce a deep-blue color with a strong character absorption peak at $651 \mathrm{~nm}$ (curve III), indicating the yield of oxTMB. These results confirmed that $\mathrm{Fe}_{3} \mathrm{O}_{4} @ \mathrm{MnO}_{2}$ NPs possessed the intrinsic oxidase-like activities, owing to the redox properties of $\mathrm{MnO}_{2}$. However, $\mathrm{Fe}_{3} \mathrm{O}_{4} @ \mathrm{MnO}_{2} \mathrm{NPs}$ could be reduced by GSH directly into $\mathrm{Mn}^{2+}$, while GSH was oxidized to glutathione disulfide (GSSG), as shown in Eq. (1).

$$
\mathrm{MnO}_{2}+2 \mathrm{GSH}+2 \mathrm{H}^{+} \longrightarrow \mathrm{Mn}^{2+}+\mathrm{GSSG}+2 \mathrm{H}_{2} \mathrm{O}
$$

Thus, in the presence of GSH, almost no blue color appears, demonstrating that the oxidation of TMB was inhibited by a rapid decomposition of $\mathrm{Fe}_{3} \mathrm{O}_{4} @ \mathrm{MnO}_{2} \mathrm{NPs}$ by GSH (curve IV). Besides, there was no significant absorption peak upon incubating $\mathrm{Fe}_{3} \mathrm{O}_{4} @ \mathrm{MnO}_{2}$ NPs with GSH in the sensing system

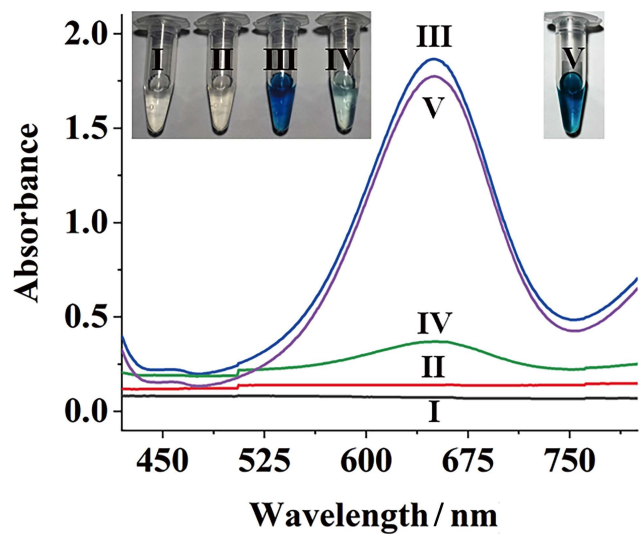

Fig. 2 UV-Vis spectra of different solutions: (I) $50 \mu \mathrm{M}$ GSH incubated with $10 \mathrm{mg} / \mathrm{mL}$ TMB, (II) $200 \mu \mathrm{g} / \mathrm{mL} \quad \mathrm{Fe}_{3} \mathrm{O}_{4} @ \mathrm{MnO}_{2}$ nanocomposite incubated with $50 \mu \mathrm{M}$ GSH, (III) $200 \mu \mathrm{g} / \mathrm{mL} \mathrm{Fe}_{3} \mathrm{O}_{4} @$ $\mathrm{MnO}_{2}$ nanocomposite incubated with $10 \mathrm{mg} / \mathrm{mL}$ TMB, (IV) $200 \mu \mathrm{g} / \mathrm{mL}$ $\mathrm{Fe}_{3} \mathrm{O}_{4} @ \mathrm{MnO}_{2}$ nanocomposite and $50 \mu \mathrm{M} \mathrm{GSH}$ incubated with $10 \mathrm{mg} / \mathrm{mL}$ TMB, (V) using the same reaction condition with (III), catalytic activity of the $\mathrm{Fe}_{3} \mathrm{O}_{4} @ \mathrm{MnO}_{2}$ nanocomposite after 6 months storage. The inset images correspond to the visual colorimetric response. Error bars represent the standard deviation of three replicates. 

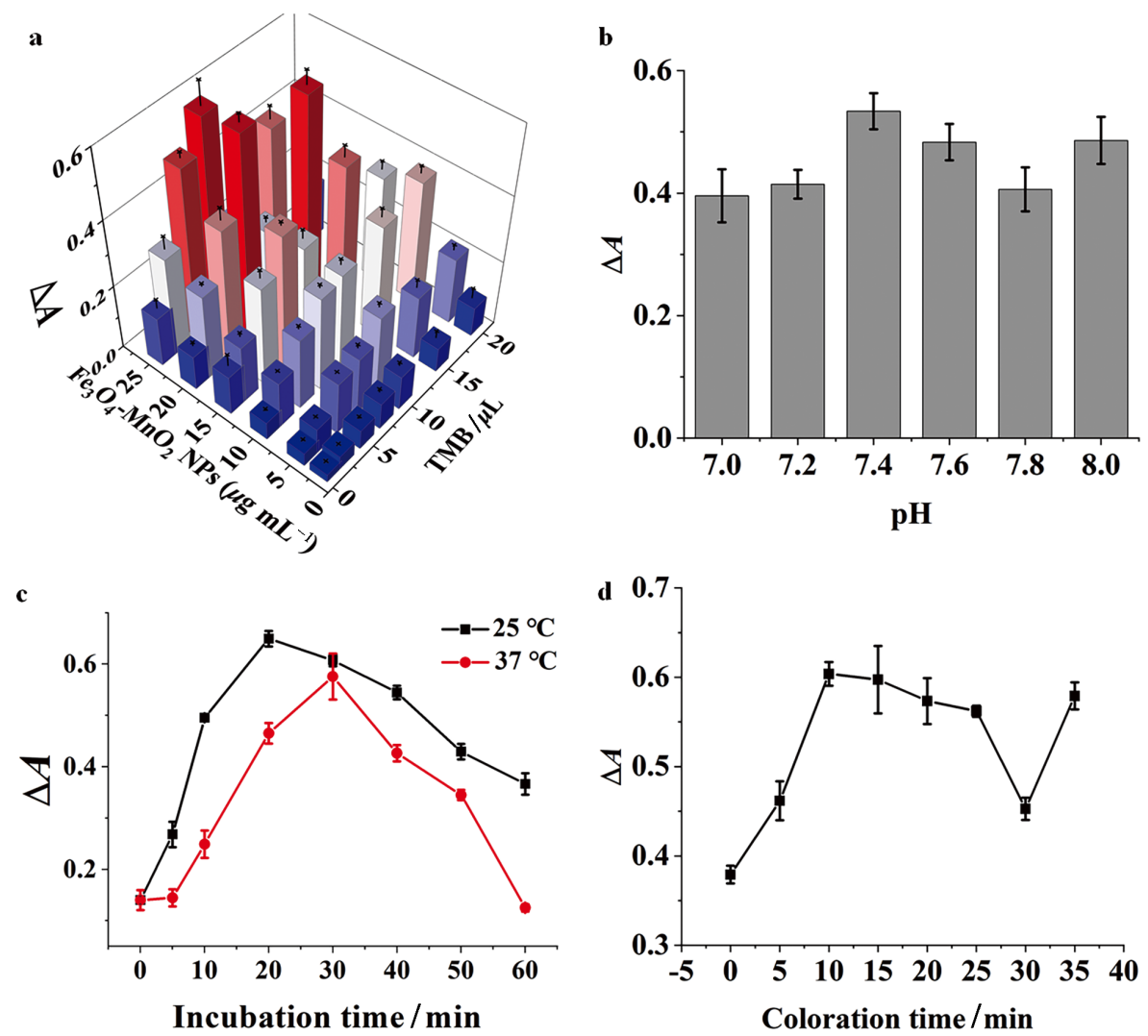

Fig. 3 Effect of: (a) the concentration of $\mathrm{Fe}_{3} \mathrm{O}_{4} @ \mathrm{MnO}_{2} \mathrm{NPs}$ and the amount of TMB; (b) pH; (c) incubation time and the reaction temperature; (d) coloration time. Error bars represent the standard deviation of three replicates.

(curve II). In addition, the long-term stability of the catalytic activity of the $\mathrm{Fe}_{3} \mathrm{O}_{4} @ \mathrm{MnO}_{2} \mathrm{NPs}$ was investigated. After 6 months of storage, the $\mathrm{Fe}_{3} \mathrm{O}_{4} @ \mathrm{MnO}_{2}$ NPs exhibited only a slight decrease in the catalytic activity (curve $\mathrm{V}$ ), indicating their easy storage and excellent long-term stability. Considering the above results, $\mathrm{Fe}_{3} \mathrm{O}_{4} @ \mathrm{MnO}_{2} \mathrm{NPs}$ can be used as a turn-off colorimetric sensor for GSH detection based on discerning the color change of oxTMB with bare eyes or recording the maximum absorption peak at $651 \mathrm{~nm}$.

\section{Optimization of sensing conditions}

To obtain the best optical sensing performance for GSH detection, the concentrations of $\mathrm{Fe}_{3} \mathrm{O}_{4} @ \mathrm{MnO}_{2} \mathrm{NPs}$ and TMB, the $\mathrm{pH}$ value, the incubation time and the reaction temperature, and the coloration time were optimized by investigating $\triangle A(\Delta A$ $=A_{0}-A$, where $A_{0}$ and $A$ are the absorbance of oxTMB at $651 \mathrm{~nm}$ in the absence and presence of GSH, respectively) prior to applying our proposed method. First, a series of different concentrations of $\mathrm{Fe}_{3} \mathrm{O}_{4} @ \mathrm{MnO}_{2} \mathrm{NPs}$ and TMB was investigated to evaluate their impact on the redox reaction. As shown in Fig. 3a, the final concentrations of $20 \mu \mathrm{g} / \mathrm{mL}$ of $\mathrm{Fe}_{3} \mathrm{O}_{4} @ \mathrm{MnO}_{2}$ NPs and $7.5 \mu \mathrm{L}$ of TMB $(10 \mathrm{mg} / \mathrm{mL})$ were used to reach the maximum $\Delta A$. Subsequently, the $\mathrm{pH}$ value is a crucial factor concerning the stability of the catalytic activity of $\mathrm{Fe}_{3} \mathrm{O}_{4} @ \mathrm{MnO}_{2}$ NPs. The optimal condition was obtained at $\mathrm{pH} 7.4$ between pH 7.0 to 8.0 (Fig. 3b). Next, the influence of the incubation time and the reaction temperature was monitored, the results are shown in Fig. 3c. It can be seen that $25^{\circ} \mathrm{C}$ for $20 \mathrm{~min}$ is the most suitable reaction condition for the assay. Finally, the coloration time was also optimized by recording $\Delta A$ with different test intervals. The $\Delta A$ dramatically increased during the first $10 \mathrm{~min}$ incubation, where thereafter, even slight decreasing was observed (Fig. 3d). Based on these results, subsequent experimental conditions were chosen to give the best results: (a) $20 \mu \mathrm{g} / \mathrm{mL}$ of $\mathrm{Fe}_{3} \mathrm{O}_{4} @ \mathrm{MnO}_{2} \mathrm{NPs}$ and $7.5 \mu \mathrm{L}$ of TMB; (b) $\mathrm{pH} \mathrm{7.4;} \mathrm{(c)} \mathrm{incubation} \mathrm{time} \mathrm{and} \mathrm{reaction} \mathrm{temperature,} 25^{\circ} \mathrm{C}$ for $20 \mathrm{~min}$; (d) coloration time, $10 \mathrm{~min}$.

\section{Colorimetric detection of GSH}

To demonstrate the performance of the detection strategy, varying concentrations of GSH ranging from 0.2 to $25 \mu \mathrm{M}$ were studied under the aforementioned optimized conditions. As presented by the images in Fig. 4a, with increasing the concentration of GSH, the color response of the sensing system gradually decreased from dark to light blue. The bare-eye limit of detection (LOD) for GSH was determined to be $0.2 \mu \mathrm{M}$. The corresponding UV-Vis spectra shows the absorbance progressive decline at $651 \mathrm{~nm}$ against the GSH concentration in the range from 0.2 to $25 \mu \mathrm{M}$ (Fig. 4b). As a result, a good linear relationship can be described as $A_{651}=-0.028 C+0.930$, with a correlation coefficient of $R^{2}=0.998$ (Fig. 4c), where $C$ is the GSH concentration in $\mu \mathrm{M}$. These consequences indicated that our turn-off colorimetric assay can be successfully applied for GSH detection with high sensitivity.

To prove that the proposed assay has good selectivity for GSH detection, the effects of some possible interfering species were investigated, including Gly, Arg, Trp, Cys and Hcy. As shown in Fig. 4d, most amino acids do not induce any obvious absorbance changes at $651 \mathrm{~nm}$, compared to GSH under the same conditions $(n=10)$. It should be noticed that the other 

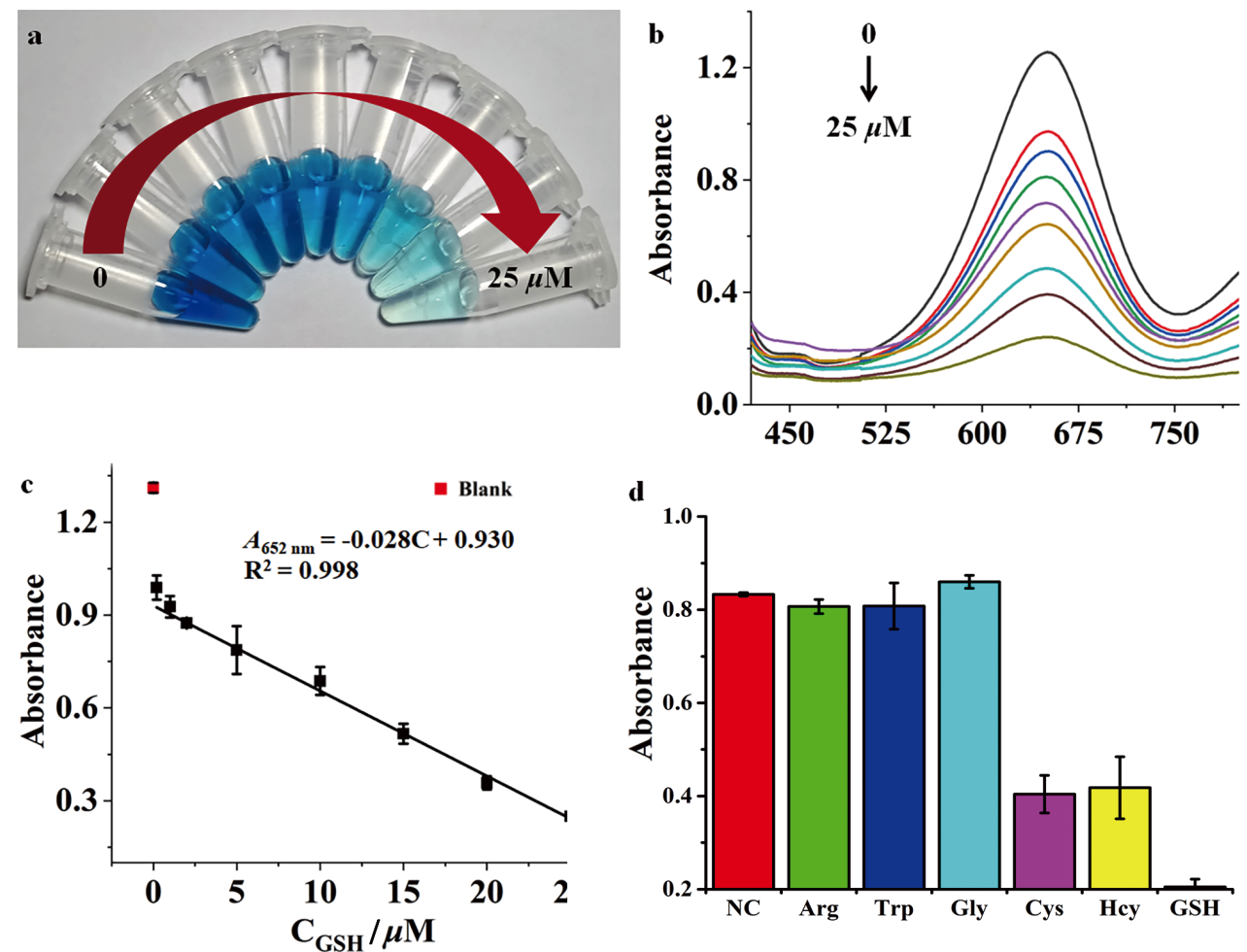

Fig. 4 (a) Photographs, (b) UV-Vis spectra of the proposed colorimetric assay after incubation with GSH at various concentrations $(0,0.2,2,5,10,15,20,25 \mu \mathrm{M})$, (c) the calibration curve for GSH (the absorbance at $651 \mathrm{~nm} v s$. the GSH concentrations), the red point is the value of Blank samples. Error bars represent the standard deviation of three replicates. (d) Selectivity test. The concentration of GSH and all other potential interfering amino acid were $25 \mu \mathrm{M}$. All measurements were acquired at $25^{\circ} \mathrm{C}$ for $30 \mathrm{~min}$ in PBS (pH 7.4). Error bars represent the standard deviation of 10 replicates.

thiol-containing amino acids, such as Cys and Hcy, can also cause a slightly decreased absorbance signal. However, the cellular levels of Cys and Hcy are extremely low, whose levels are a thousand-times lower than that of $\mathrm{GSH},{ }^{34}$ and can be negligible in a cellular GSH evaluation. Besides, the stability of the method was verified by detecting GSH at $25 \mu \mathrm{M}$ in $1,4,7$, 14, 21, 28 days. According to Fig. S3, the response of our assay toward to GSH day to day had only a small change difference within 28 days, and the RSD was $2.5 \%$, calculated by the absorbance at $651 \mathrm{~nm}(n=10)$. These results showed good stability of our assay. In general, our proposed assay based on $\mathrm{Fe}_{3} \mathrm{O}_{4} @ \mathrm{MnO}_{2} \mathrm{NPs}$ as a nanosensor can achieve selective GSH detection without significant interference.

\section{GSH evaluation in cell samples}

The applicability of the $\mathrm{Fe}_{3} \mathrm{O}_{4} @ \mathrm{MnO}_{2}$ NPs-TMB system was further explored by detecting the GSH concentration in three human cell lines, including one normal cell line (HUVEC) and two cancer cell lines (SMMC-7721 and HepG-2) as the model. We used our approach to evaluate cellular GSH levels and, also employed a commercial GSH assay kit for a comparison. As displayed in Fig. 5, the quantitative results show that there is no significant difference between this assay and the commercial kit ( $p>0.05$ ), demonstrating the excellent accuracy and reliability of our approach for detecting GSH in cell samples $(n=10)$. Furthermore, all of the experimental results revealed that the overall GSH levels in cancer cells were much higher than that in normal cells, which was quite consistent with previous reports. ${ }^{6,35}$ Thus, our assay developed here can provide a straightforward and reliable protocol to accurately evaluate the cellular GSH

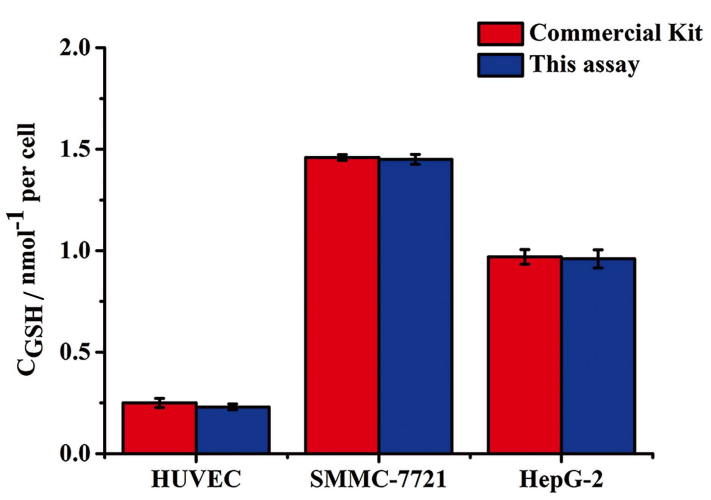

Fig. 5 Comparison of GSH levels in different cell lines evaluated by a commercial GSH assay kit and this assay. All cells were evaluated with equal amounts of cell lysate. Error bars represent the standard deviation of 10 replicates.

Table 1 Comparison of GSH detection by commercial GSH assay kit and our assay

\begin{tabular}{lll}
\hline & \multicolumn{1}{c}{ Commercial kit } & \multicolumn{1}{c}{ Our assay } \\
\hline Total detection time & $30-65 \mathrm{~min}$ & $25 \mathrm{~min}$ \\
LOD & $1 \mu \mathrm{M}$ & $0.2 \mu \mathrm{M}$ \\
Storage conditions & $-20^{\circ} \mathrm{C}\left(\mathrm{NADPH}-70^{\circ} \mathrm{C}\right)$ & $4^{\circ} \mathrm{C}$ \\
Reaction temperature & $25^{\circ} \mathrm{C}$ & $25^{\circ} \mathrm{C}$ \\
Shelf life & 3 months & At least 6 months \\
Detection cost & $\sim \$ 0.59 /$ sample & $\sim \$ 0.014 /$ sample \\
\hline
\end{tabular}


levels so as to assess whether it is a cancer or normal cell. As listed in Table 1 and Table S1, compared to the commercial GSH assay kit and other approaches, our one-step optical sensing system offers some distinguished advantages in terms of the ease of operation, low-cost and time-saving.

\section{Conclusion}

In summary, a $\mathrm{Fe}_{3} \mathrm{O}_{4} @ \mathrm{MnO}_{2}$ nanocomposite was synthesized. The possessed a high oxidase-like catalytic activity, and could oxidize TMB to form a blue-colored production oxTMB in a neutral solution. GSH was able to trigger decomposition of the component of $\mathrm{MnO}_{2}$, with a remarkable inhibition effect and enzymatic properties, resulting in a decrease of absorbance intensity of the TMB substrate chromogenic system. Therefore, a sensitive and selective colorimetric strategy for GSH sensing was fabricated. The proposed method provides a wide linear range of from 0.2 to $25 \mu \mathrm{M}$ with a LOD as low as $0.2 \mu \mathrm{M}$. It was successfully applied for detecting intracellular GSH. Importantly, our one-step approaches have no need for any procedures of separation and washing, no needs for $\mathrm{H}_{2} \mathrm{O}_{2}$, and has no special requirement for the $\mathrm{pH}$ and temperature. It can be assumed that this strategy has great potential as an effective tool for clinical diagnosis and even therapy related to GSH.

\section{Acknowledgements}

We thank Dr. Wei Wang (Central South University, Changsha, China) for experimental assistance. The authors are thankful for the financial support from the National Natural Science Foundation of China (Grant No. 82073603 and 82073557), Jilin Province Science and Technology Development Plan Item (Grant No. 20200403035SF).

\section{Conflicts of Interest}

The authors declare no conflict of interests.

\section{Supporting Information}

This material is available free of charge on the Web at http:// www.jsac.or.jp/analsci/.

\section{References}

1. A. Meister, J. Biol. Chem., 1988, 263, 17205.

2. W. J. Niu, R. H. Zhu, S. Cosnier, X. J. Zhang, and D. Shan, Anal. Chem., 2015, 87, 11150.

3. A. L. Ortega, S. Mena, and J. M. Estrela, Cancers (Basel), 2011, 3, 1285.

4. Z. Z. Dong, L. H. Lu, C. N. Ko, C. Yang, S. N. Li, M. Y. Lee, C. H. Leung, and D. L. Ma, Nanoscale, 2017, 9, 4677.

5. Y. L. Xianyu, Y. Z. Y. Xie, N. X. Wang, Z. Wang, and X. Y. Jiang, Small, 2015, 11, 5510.

6. U. Keitaro, Y. Masafumi, K. Mako, Y. Tatsuya, and U.
Yasuteru, Nat. Chem., 2017, 9, 279.

7. E. Detsri and P. Seeharaj, Colloids Surf., A, 2017, 533, 125.

8. J. J. Gu, D. H. Hu, W. N. Wang, Q. H. Zhang, Z. Meng, X. D. Jia, and K. Xi, Biosens. Bioelectron., 2015, 68, 27.

9. R. Kandar, M. Vrbova, and J. Candova, J. Liq. Chromatogr. Relat. Technol., 2013. 36, 2013.

10. A. Niemz, T. M. Ferguson, and D. S. Boyle, Trends Biotechnol., 2011, 29, 240.

11. Q. Y. Liu, Y. T. Yang, H. Li, R. R. Zhu, Q. Shao, S. G. Yang, and J. J. Xu, Biosens. Bioelectron., 2015, 64, 147.

12. Y. N. Ding, B. C. Yang, H. Liu, Z. X. Liu, X. Zhang, X. W. Zheng, and Q. Y. Liu, Sens. Actuators, B, 2018, 259, 775.

13. X. X. Zhu, W. Chen, K. L. Wu, H. Y. Li, M. Fu, Q. Y. Liu, and X. Zhang, New J. Chem., 2018, 42, 1501.

14. S. C. Lin, Y. H. Zhang, W. Cao, X. Y. Wang, L. Qin, M. Zhou, and H. Wei, Dalton Trans., 2019, 48, 1993.

15. N. Singh, M. Geethika, S. M. Eswarappa, and G. Mugesh, Chem. Eur. J., 2018, 24, 8393.

16. A. Mohamad, N. A. Keasberry, and M. U. Ahmed, Anal. Sci., 2018, 34, 1257.

17. L. Z. Gao, J. Zhuang, L. Nie, J. B. Zhang, Y. Zhang, N. Gu, T. H. Wang, J. Feng, D. 1. Yang, S. Perrett, and X. Y. Yan, Nat. Nanotechnol., 2007, 2, 577.

18. K. Fan, H. Wang, J. Xi, Q. Liu, X. Meng, D. Duan, L. Gao, and X. Yan, Chem. Commun., 2016, 53, 424.

19. M. Jang, W. Chen, and F. S. Cannon, Environ. Sci. Technol., 2008, 42, 3369.

20. J. S. Yamani, S. M. Miller, M. L. Spaulding, and J. B. Zimmerman, Water Res., 2012, 46, 4427.

21. T. Wu, Z. Ma, P. Li, M. Liu, X. Liu, H. Li, Y. Zhang, and S. Yao, Talanta, 2019, 202, 354.

22. K. Yang, M. Zeng, X. Hu, B. Guo, and J. Zhou, Analyst, 2014, 139, 4445.

23. Y. S. Liu, C. Zhao, X. L. Song, K. Xu, J. Wang, and J. Li, Microchim. Acta, 2017, 184, 4785 .

24. X. Yan, Y. Song, X. Wu, C. Zhu, X. Su, D. Du, and Y. Lin, Nanoscale, 2017, 9, 2317.

25. H. Jiang, X. Su, Y. Zhang, J. Zhou, D. Fang, and X. Wang, Anal. Chem., 2016, 88, 4766.

26. Z. Ma, T. Wu, P. Li, M. Liu, S. Huang, H. Li, Y. Zhang and S. Yao, Microchim. Acta, 2019, 186, 498.

27. Y. Xiong, S. Chen, F. Ye, L. Su, C. Zhang, S. Shen, and S. Zhao, Anal. Methods, 2015, 7, 1300.

28. Q. Wang, H. Pang, Y. Dong, Y. Chi, and F. Fu, Microchim. Acta, 2018, 185, 291.

29. X. L. Zhang, C. Zheng, S. S. Guo, J. Li, H. H. Yang, and G. Chen, Anal. Chem., 2014, 86, 3426.

30. Y. Liu, Q. Jia, Q. Guo, W. Wei, and J. Zhou, Biomaterials, 2018, 180, 104.

31. L. Zhang, J. Lian, L. Wu, Z. Duan, J. Jiang, and L. Zhao, Langmuir, 2014, 30, 7006.

32. X. Yang, Y. Makita, Z. Liu, K. Sakane, and K. Ooi, Chem. Mater, 2004, 16, 5581.

33. T. C. Brunold, D. R. Gamelin, T. L. Stemmler, S. K. Mandal, W. H. Armstrong, J. E. Penner-Hahn, and E. I. Solomon, J. Am. Chem. Soc., 1998, 120, 8724.

34. Q. Tang, N. Wang, F. Zhou, T. Deng, S. Zhang, J. Li, R. Yang, W. Zhong, W. Tan, Chem. Commun., 2015, 51, 16810.

35. R. R. Perry, J. A. Mazetta, M. Levin, and S. C. Barranco, Cancer, 1993, 72, 783. 